\title{
Blindness and visual impairment in a rural community in Ogun State, South West Nigeria
}

\author{
*Hassan MB. ${ }^{1}$, Adejumo OO. ${ }^{2}$
}

\begin{abstract}
Objectives: This is a community-based study in which residents of Coker-Ilepa ward of Ifo Local Government Area of Ogun State, South-West Nigeria were examined to determine the prevalence of blindness and visual impairment serving as a screening exercise contributing to primary eye care programme of the community. The study aims to find out the prevalence and pattern of blindness and visual impairment in this community and to compare and contrast with other studies.
\end{abstract}

Methods: Five hundred and four (504) residents from 8 villages selected via multi-stage random sampling were interviewed and examined over a 15 day period and results analyzed with WHO Epi-Info 2002 software.

Results: Prevalence of blindness was $2.2 \%$ (95\% CI $0.89-3.50, \mathrm{n}=504)$ while that of visual impairment was $8.9 \%$ (95\% CI 6.36 - 11.44, $\mathrm{n}=504)$. Blindness was also higher in the elderly $(8.8 \%$ in those above 60 years compared to $1.4 \%$ in those between $40-49$ years and $0 \%$ in those less than 40 years) and in females $(3.5 \%)$ as against males $(0.81 \%)$. Cataract is the commonest cause of blindness and visual impairment $72.7 \%$ and $46.7 \%$ respectively followed by corneal scarring for blindness $(18.2 \%)$ with refractive error being the second cause of visual impairment (26.7\%). Glaucoma is the third most common cause of blindness $(9.1 \%)$ and visual impairment $(11.1 \%)$ respectively.

Conclusion: - The study shows a very high prevalence of blindness and with cataract responsible. The provision of adequate modern eye care facilities with surgical capabilities in the rural area in order to achieve the goals of Vision 2020 in the country is therefore recommended.

Key Words: - Blindness, Visual, impairment, rural.

*Correspondence Author: Dr Mustapha B Hassan, Email: mustapha.hassan@uniosun.edu.ng

${ }^{1}$ Department of Surgery, College of Health Sciences, Osun State University Osogbo, Nigeria.

${ }^{2}$ Department of Ophthalmology, Ladoke Akintola University of Technology Teaching Hospital, Osogbo, Nigeria.

Research Journal of Health Sciences subscribed to terms and conditions of Open Access publication. Articles are distributed under the terms of Creative Commons Licence (CC BY-NC-ND 4.0). (http://creativecommons.org/licences/by-nc-nd/4.0).

http://dx.doi.org/10.4314/wsa.v4i3.5 


\title{
Cécité et déficience visuelle dans une communauté rurale dans l'Etat d'Ogun, sud-ouest du Nigeria
}

\author{
*Hassan MB. ${ }^{1}$, Adejumo OO. ${ }^{2}$
}

\section{Resume}

Objectifs: Cette étude est axée sur la communauté dans laquelle les résidents de Coker-Ilepa pupille de Ifo région de gouvernement local de l'Etat d'Ogun, Sud-Ouest du Nigeria ont été examinés afin de déterminer la prévalence de la cécité et des déficiences visuelles servant comme un exercice de dépistage contribuant à l'œil primaire programme de la communauté des soins. L'étude vise à déterminer la prévalence et le motif de la cécité et des déficiences visuelles dans cette communauté et de confronter avec d'autres études.

Méthodes: Cinq cent quatre (504) résidents de 8 villages sélectionnés par plusieurs étapes d'échantillonnage aléatoire ont été interrogés et examinés sur une période de 15 jours et les résultats analysés avec l'OMS Epi-Info logiciels 2002.

Résultats: La prévalence de la cécité est de 2,2\% (IC 95\% 0,89 à 3,50, $\mathrm{n}=504$ ), tandis que celui de la déficience visuelle était de $8,9 \%$ (IC à $95 \% 6,36$ à $11,44, \mathrm{n}=504$ ). Cécité était également plus élevé chez les personnes âgées $(8,8 \%$ chez les plus de 60 ans, comparativement à 1,4\% chez ceux entre $40-49$ ans et $0 \%$ chez les moins de 40 ans) et chez les femmes $(3,5 \%)$ que contre les hommes $(0,81 \%)$. La cataracte est la principale cause de cécité et de déficience visuelle - $72,7 \%$ et $46,7 \%$, respectivement, suivis par la cicatrisation de la cornée de la cécité $(18,2 \%)$ avec l'erreur de réfraction étant la deuxième cause de déficience visuelle $(26,7 \%)$. Le glaucome est la troisième cause la plus fréquente de cécité $(9,1 \%)$ et la déficience visuelle $(11,1 \%)$, respectivement.

Conclusion: L'étude montre une très forte prévalence de la cécité et de la cataracte responsable. La fourniture d'installations modernes de soins oculaires adéquats avec des capacités chirurgicales dans la zone rurale afin d'atteindre les objectifs de Vision 2020 dans le pays est donc recommandé.

Mots clés: Cécité, Visual, dépréciation, rural.

*Authur Correspondant: Dr Mustapha B Hassan, Email: mustapha.hassan @uniosun.edu.ng

${ }^{1}$ Department of Surgery, College of Health Sciences, Osun State University Osogbo, Nigeria.

${ }^{2}$ Department of Ophthalmology, Ladoke Akintola University of Technology Teaching Hospital, Osogbo, Nigeria. 


\section{INTRODUCTION}

Blindness is a major health problem that has received worldwide attention in other to promote health (1). Globally, 32.4 million people were blind in 2010, and 191 million people had moderate and severe visual impairment and the global initiative, Vision 2020, predicts that the number of blind people will increase dramatically by the year 2020 (2).

Most of the world's blind live in the developing countries (2) like in Western SubSaharan Africa, Eastern Sub-Saharan Africa, South Asia, North Africa and the Middle East where prevalence is 10 per 1000 whereas in Europe the prevalence of blindness is 0.33 per 1000 (3) with the associated burden being a relatively huge problem in the developing world. The global prevalence of childhood blindness is $0.78 / 1,000$ children ( 3 ), and there are estimated to be 1.5 million blind children (3), three-quarters of whom also live in the developing countries. More than two-thirds of blindness is avoidable with Cataract as the major cause followed by glaucoma and thirdly diabetic retinopathy with the reduction in trachoma hitherto number 3 (1).

Blindness is a significant burden to society with attendant high cost of lost productivity, rehabilitation and education. The cost of preventing blindness is only a small fraction of this making the cost effectiveness of preventive measures very high. Timely and effective utilization of resources for the prevention of blindness will thus provide enormous savings in both financial and human suffering; improves quality of life and thus raise low life expectancy associated with blindness in the developing countries (4).

To establish a blindness control and prevention programme in any community, reliable demographics of blindness are essential which according to WHO (1), can be ascertained through a community-based prevalence surveys. This has been recommended for developing a national programme for control and elimination of avoidable blindness, if the goals of Vision 2020 are to be achieved (1).

This study is aimed at determining the magnitude of blindness and visual impairment; its demographic pattern, causes, as well as the predisposing factors in a rural community in Nigeria with Coker-Ilepa ward of Ifo Local Government Area of Ogun State as a typical rural community. As the figures provided by the National survey are regional and national average, this study provides a coned down figure to serve as a data base for the planning and execution of eye care services in the affected community.

\section{MATERIALS AND METHODS}

This is a community based descriptive cross sectional study in a rural community in Nigeria. It was among residents of Coker-Ilepa Ward of Ifo Local Government Area of Ogun State, in the Southwestern part within latitudes $6^{0}$ $\mathrm{N}$ and $71 \frac{1}{2} \mathrm{~N}$, longitudes $21 / 2^{0} \mathrm{E}$ and $5^{0} \mathrm{E}$. The area is in the rain forest zone of the country and bounded by Ewekoro LGA in the North, Obafemi-Owode LGA in the East, Ado Odo-Otta LGA in the South and Egbado South LGA in the West respectively - Figure 1. It comprises of 29 villages each consisting of 10 to 40 houses (5). There is a primary health care centre outpost of the Lagos University Teaching Hospital located in one of the villages - Pakoto. The inhabitants depend on two streams for their water supply. It is essentially an agrarian community with a few artisans who engage in other works like carpentry, welding, etc.

The current definition of Blindness as proposed by WHO In 1975 and included in the International Classification of Diseases (ICD10 ), is utilized for this study with blindness defined as best corrected visual acuity of less than $3 / 60$ in the better eye (i.e. less than $3 \mathrm{mCF}$ ) or visual field of $<10^{\circ}$ from the point of fixation (5) while Visual impairment is defined as best corrected visual acuity of $<6 / 18$ but better than or equal to $3 / 60(6)$.

The sample size was 504 individuals calculated using the Leslie Fischer formula $\mathrm{N}=\mathrm{Z}_{\mathrm{i}^{-}}$ $@^{2} p(1-p) / d^{2}$ based on the National estimated blindness Prevalence rate of $1.3 \%(7,8)$. The study population are people who had resided continuously in the community for at least 6 months preceding the study and were drawn out of the target population via a multistage random sample of cluster of households with all residents of all ages in each clusters used for this study.

Ethical approval was obtained from Lagos University Teaching Hospital while verbal informed consent was also obtained from each subject interviewed and examined. The community entry was undertaken by the survey team paying a courtesy visit to the Chiefs and "Baales" of each of the selected villages to seek their permission during which they were also availed of free eye and medical screening.

The Sampling Unit is the household with the study sample chosen by multistage random 
sampling. In the first stage, the 29 villages were arranged in alphabetical order. Five of them were selected using systematic sampling of every $6^{\text {th }}$ village beginning from the first village on the list. One hundred respondents were to be interviewed from each of the 5 villages. In the second stage of the sampling, the respondents were chosen by interviewing all individuals resident in a cluster of consecutive household until the sample size was reached. The first household was randomly chosen by selecting the household number that correspond to the last digit of the number on a currency note picked from the Principal Investigator's pocket. It was later discovered that the population available in some of the selected villages were not up to the required sample size, hence the nearest adjoining village was then added to make up the sample size. In all 8 villages and 136 households were used with a total sample size of 504 .

The survey team was selected from the PHC workers of LUTH stationed in Pakoto primary Health centre and trained on simple eye examination like visual acuity testing and pen touch examination. Data was then collected over a 15-day period after the training. Data collection was done near the subjects home by the use of a Structured Interviewer Administered Questionnaire to collect Demographic information like age, sex, occupation etc. while WHO Prevention of Blindness eye examination record-version III of 1988 (9) was used for the ocular examination.

Data was analyzed with Epi-Info Version 2002 statistical package. Demographic characteristics were compared between blindness, visually impaired and normal subjects. The Chi square was used to assess differences in categorical variables between groups and pvalues $<0.05$ were considered statistically significant.

\section{RESULTS}

Eight out of 29 villages and 136 households randomly selected were used with a total sample size of 504 .

\section{Socio-Demographic pattern}

The socio-demographic characteristics of the sample population are as shown in Figure 2 and Table 1. Figure 2 shows the age distribution of the population indicating that people between the ages of 10-19 years constitute the highest group $(23.8 \%)$ while the elderly above 70 years have a lower representation (12.3\%).
Males were $247(49.0 \%)$ while the females were $257(51.0 \%)$. There was a male to female ratio of 1:1.04 indicating a slight female preponderance though not statistically significant. A large number of the population $146(29.0 \%)$ had no formal education according to the WHO criteria for minimum literacy level (completed primary education and above) which put the literacy level of the sample at $43.7 \%$. Occupationally, students were 224 constituting $44.4 \%$. This was followed by farmers -116 $(23.0 \%)$ and traders 93 (18.5\%). Others include artisans, full time housewives and unemployed constituting $71(14.1 \%)$.

\section{Pattern of Blindness and Visual Impairment}

Blindness had a prevalence of $2.2 \%$, (95\% CI $0.89-3.50$, freq $11, \mathrm{n}=540$ ) in the sampled population while Uni-ocular Blindness has a prevalence of $2.8 \%$ (95\% CI $1.5-4.3$, freq 14 , $\mathrm{n}=540$ ) with Bilateral visual impairment having a prevalence of $8.9 \%$ (95\% CI 6.36 - 11. 44, freq $45, \mathrm{n}=540$ ) while the prevalence of uniocular visual impairment is $1.4 \%$ (95\% CI $0.35-2.45$, freq $7, n=540$ ) as shown in Table 2 .

The prevalence of blindness and visual impairment increases with age. There is no blindness in age groups below 40 years while people between 40 - 59 years of age have blindness prevalence of $1.4 \%$, and people above 60 years have a prevalence of $8.8 \%$ which is statistically significant (chi-square $=32.72>3.84$, $\mathrm{P}<0.05)$ as in Table 3.

The sex distribution of blindness and visual impairment highlight the fact that women are more affected than men, with the exception of uniocular visual impairment which shows a male preponderance. For blindness, the prevalence in women is $3.50 \%$ while that of men is $0.81 \%$ showing a significance statistically (chi-square $=$ $4.27>3.84, \mathrm{P}<0.05$ ) as shown in Table 4.

\footnotetext{
Aetiology of Blindness and Visual Impairment

Cataract is the commonest cause of blindness and visual impairment - uniocular blindness $-42.9 \%$, blindness $-72.7 \%$, unilateral visual impairment $57.1 \%$ and bilateral visual impairment $46.7 \%$; followed by corneal scarring $(18.2 \%)$ as a cause of blindness while refractive error is the second commonest cause of bilateral visual impairment (26.7\%). Glaucoma is the third commonest cause of blindness (9.1\%) and visual impairment $(11.1 \%)$ - Tables 5.
} 


\section{DISCUSSION}

The study area is a rural population with nonexistent eye care as the Primary health Care Centre in Pakoto has no trained eye care personnel among its workforce. The age distribution of this population is a typical developing countries pattern with a wide base that tapers towards the top indicating a preponderance of younger generation over the older generation with $36.7 \%$ of the sample falling below 20 years, $35.3 \%$ lies between $20-49$ years while $28 \%$ are above 50 years.

The literacy level is low where only $43.7 \%$ of the study population has completed primary education - a reflection of the rural nature of the area of study and majority of the study population are students (44.4\%) followed by adults who are farmers $(23.0 \%)$ which explain why the income level is very low and thus access to healthcare may be impaired.

The prevalence of blindness found in this study is $2.2 \%$ (95\% CI, $0.89 \%$ to $3.5 \%$ ). This is thrice the national average rate of .78\% (7). This level of prevalence is higher than the expected average of $1.6 \%$ for the South but closer to the expected average of $2.0 \%$ for the Northern part of the country. This may be attributable to the second most common cause of blindness discovered in this study (Corneal opacity) which is similar to what is reported in the north; however prevalence in this study is in agreement with values reported in other developing countries, which must be treated with caution as surveys on blindness are sensitive to the definitions used in the population of study.

Prevalence of uniocular blindness is $2.8 \%$. However, this is lower than $34.7 \%$ found in South Africa (10) - a more industrialized country than Nigeria though the later is a hospital based study. Prevalence of visual impairment found in this study is $8.9 \%$ for bilateral cases. Different values have also been reported in literature especially in the developing countries ranging from $3.4 \%$ for bilateral low vision by Rabiu in Kaduna in Northern Nigeria (11) to $5.5 \%$ reported in South-south region (9) and $17.1 \%$ in Tema, Ghana - an area sharing similar geographic characteristics (12). For unilateral low vision, the prevalence in this study is $1.4 \%$.

The results of the study also showed a rising blindness prevalence rate with advancing age which is in agreement with the reported studies all over the world $(8,9,10$, and 12) with the prevalence in people over 60 years being $8.8 \%$. The results also show statistically significant difference between males and females
$($ chi square $=4.27>3.84 \mathrm{P}<0.05)$ with $0.8 \%$ blindness prevalence in males and $3.5 \%$ in females. This is also in agreement with some studies reported in other parts of the country for example in South - south (9). The female preponderance of blindness could be attributed to the fact that culturally, males are more likely to seek medical attention than females in this part of the world. Scientists have also theorized that poverty, infectious disease, and lack of access to health care services are contributory factors causing increased eye diseases in females in developing countries. Two of these factors namely poverty and lack of access to healthcare are predominant in this particular community thus contributing to high female prevalence of blindness.

In this study, cataract is the most common cause of blindness and visual impairment accounting for $72.7 \%$ and $46.7 \%$ respectively; similar to studies all over the world $(4,7,11-14)$. This is followed by corneal scarring (18.2\%). This contradicts the prevalent notion that glaucoma is the second most common cause of blindness in the southern region. This apparent contradiction could be attributed to one of the limitations of the study with respect to diagnosis of glaucoma though the corneal scarring in this study could not be attributed to trachoma as there was no evidence of trachoma in this community. Further enquiry revealed that most of the corneal scarring is secondary to injuries sustained in work places especially in farming activities. Refractive error accounts for the second commonest cause of visual impairment $(26.7 \%)$.

Glaucoma is the third common cause of blindness $(9.1 \%)$ and visual impairment $(11.1 \%)$ in this study. This could be due to underestimation in this study due to limited methods of assessment as mentioned earlier. The small sample size may also account for the low prevalence of glaucoma. Other causes of blindness and visual impairment discovered in the study included phthisis bulbi (mainly from trauma), uncorrected aphakia, macular degeneration and vascular retinopathy (mainly from hypertension).

\section{CONCLUSION}

This study shows that the prevalence of blindness in Coker-Ilepa ward of Ifo Local Government Area of Ogun State is 2.2\% while that of visual impairment is $8.9 \%$ and these rises with increasing age with more females affected than males in this particular ward.

Also the high prevalence of refractive 
error $(26.7 \%)$ in this environment is an indication of poor availability of eye care services in the area. As expected, cataract is the most common cause of blindness and visual impairment in this ward while glaucoma is the third common cause of blindness and visual impairment as opposed to other studies.

The establishment of eye care services with capabilities for cataract surgical outreach programme is hereby recommended for this area, especially at Pakoto Primary health Center. This will make eye care available to the people of the area and also help to clear the cataract backlog which is responsible for the majority of blindness and visual impairment.

Use of educational materials on causes of blindness by healthcare workers will also help to sensitize the people towards improving their accessibility of healthcare services as a lot can still be done to realize the goals of vision 2020 , the right to sight, as enunciated by World Health Organization/Prevention of Blindness (WHO/PBL) programme.

\section{REFERENCES}

1. Klauss V, Schaller UC. International initiatives for the prevention of blindness. Ophthalmologe. 2007 Oct; 104(10):855-9.

2. Stevens GA, White RA, Flaxman SR, Price H, Jonas JB, Keeffe J, et al. Vision Loss Expert Group. Global prevalence of vision impairment and blindness: magnitude and temporal trends, 1990-2010. Ophthalmology. 2013 Dec; 120(12):2377-84.

3. Guthoff RF, Schittkowski MP. Childhood blindness. VISION 2020 and experiences in an African city. Ophthalmologe. 2007 Oct; 104(10):849-54.

4. Tafida A, Kyari F, Abdull MM, Sivasubramaniam S, Murthy GV, Kana I, et al. Nigeria National Survey of Blindness and Visual Impairment Study Group Poverty and Blindness in Nigeria: Results from the National Survey of Blindness and Visual Impairment. Ophthalmic Epidemiol. 2015; 22(5):333-41.

5. National Population Commission. Census Data Release. 2006.

6. Adegbehingbe BO, Fajemilehin BR, Ojofeitimi EO, Bisiriyu LA. Blindness and visual impairment among the elderly in IfeIjesha zone of Osun State, Nigeria. Indian J Ophthalmol. 2006 Mar; 54(1):59-62.

7. Babalola OE. The peculiar challenges of blindness prevention in Nigeria: a review article. Afr J Med Sci. 2011 Dec; 40(4):309-19.

8. Entekume G, Patel J, Sivasubramaniam S, Gilbert CE, Ezelum CC, Murthy GV, et al. Nigeria National Blindness and Visual Impairment Study Group Prevalence, causes, and risk factors for functional low vision in
Nigeria: results from the national survey of blindness and visual impairment. Invest Ophthalmol Vis Sci. 2011 Aug 24; 52(9):67149.

9. Ejimadu CS, Adio AO. The burden of low vision in farming communities in South-South Nigeria. Niger J Med. 2012 Apr-Jun; 21(2):218-22.

10. Maake MM, Oduntan OA. Prevalence and causes of visual impairment in patients seen at Nkhensani Hospital Eye Clinic, South Africa. Afr J Prim Health Care Fam Med. 2015 Dec 9; 7(1):728.

11. Rabiu MM. Prevalence of blindness and low vision in north central, Nigeria. West Afr J Med. 2008 Oct; 27(4):238-44.

12. Budenz DL, Bandi JR, Barton K, Nolan W, Herndon L, Whiteside-de Vos J, et al. Tema Eye Survey Study Group Blindness and visual impairment in an urban West African population: the Tema Eye Survey. Ophthalmology. 2012 Sep; 119(9):1744-53.

13. Ngondi J, Ole-Sempele F, Onsarigo A, Matende I, Baba S, Reacher $M$, et al. Prevalence and causes of blindness and low vision in southern Sudan. PLoS Med. 2006 Dec; 3(12)

14. Sijuwola O, Fasina O. Etiology of visual impairment among ophthalmic patients at Federal Medical Center, Abeokuta, Nigeria. J West Afr Coll Surg. 2012 Oct; 2(4):38-50. 
Table 1: Socio Demographic Data of the Study Population

$\begin{array}{lcc} & \text { Number } & \text { Percentage } \\ \text { Sex } & 247 & 49.0 \\ \text { Male } & 257 & 51.0 \\ \text { Female } & & \\ & & \\ \text { Level of education } & 146 & 29.0 \\ \text { None } & 138 & 27.4 \\ \text { Primary (uncompleted) } & 84 & 16.7 \\ \text { Primary (completed) } & 62 & 12.3 \\ \text { Secondary (uncompleted) } & 52 & 10.3 \\ \text { Secondary (completed) } & 22 & 4.4 \\ \text { Post-Secondary } & & \\ & & \\ \text { Occupation } & 224 & 44.4 \\ \text { Schooling } & 116 & 23.0 \\ \text { Farming } & 93 & 18.5 \\ \text { Trading } & 71 & 14.1 \\ \text { Others } & \mathbf{5 0 4} & \mathbf{1 0 0 . 0} \\ \text { Total } & \end{array}$

Table 2: Prevalence of Blindness and Visual Impairment

$\begin{array}{lccc}\text { Diagnosis } & \text { Frequency } & \text { Prevalence (\%) } & \text { 95\% Confidence } \\ \text { Normal } & 427 & 84.7 & \\ \text { Uniocular blindness } & 14 & 2.8 & 1.50-4.30 \\ \text { Blindness } & 11 & 2.2 & 0.89-3.50 \\ \text { Uniocular visual impairment } & 7 & 1.4 & 0.35-2.45 \\ \text { Bilateral visual impairment } & 45 & 8.9 & 6.36-11.4 \\ \text { Total } & \mathbf{5 0 4} & \mathbf{1 0 0 . 0} & \end{array}$




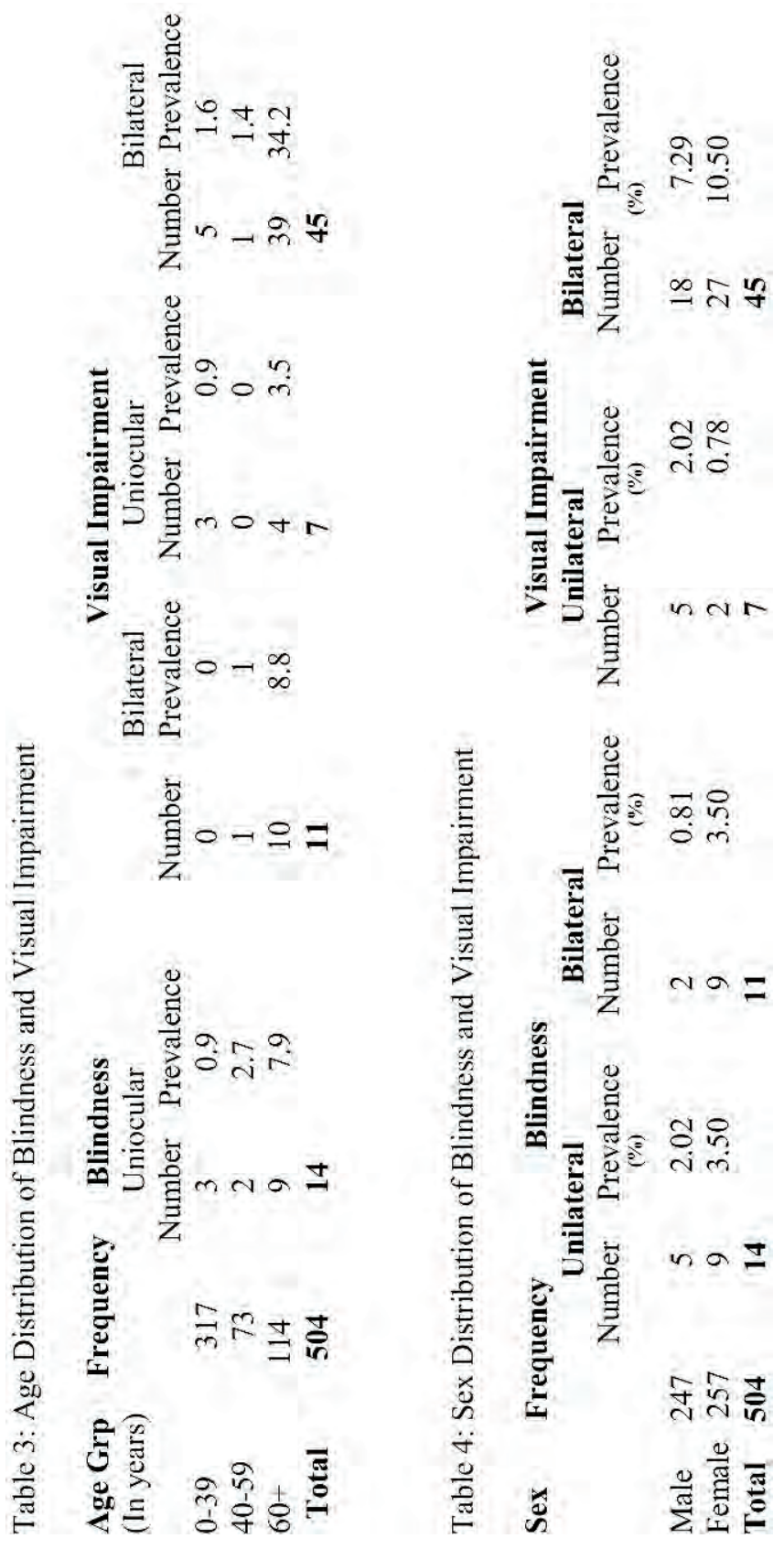




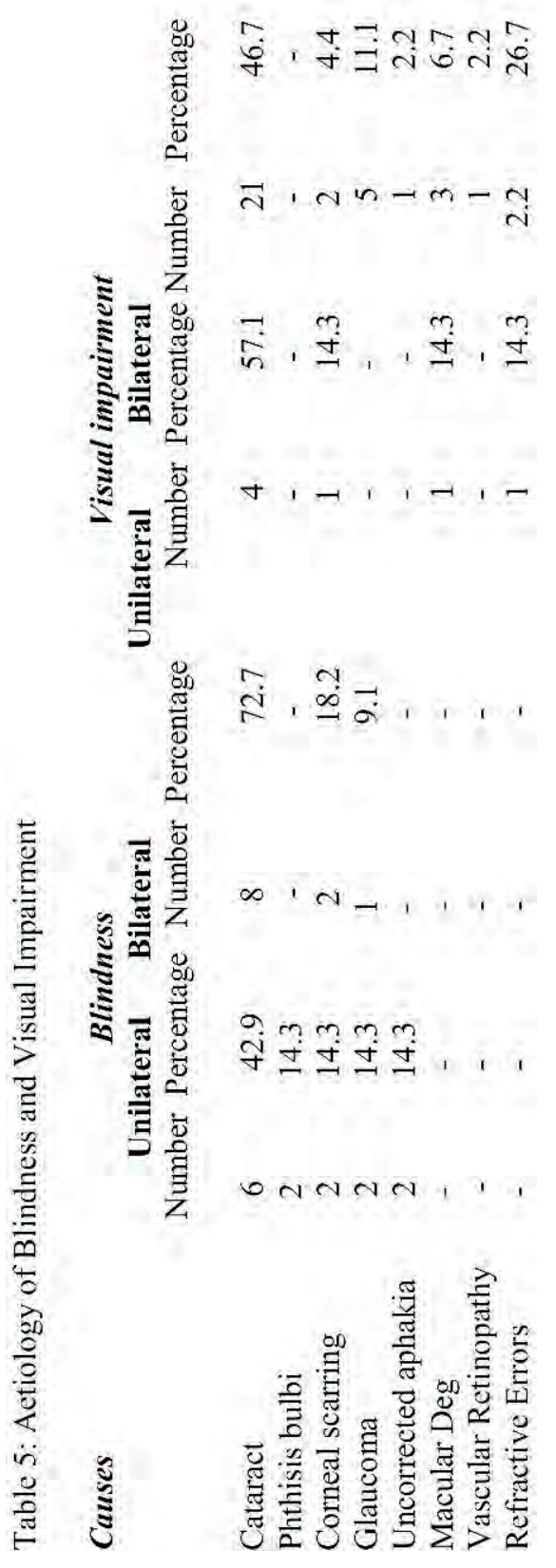




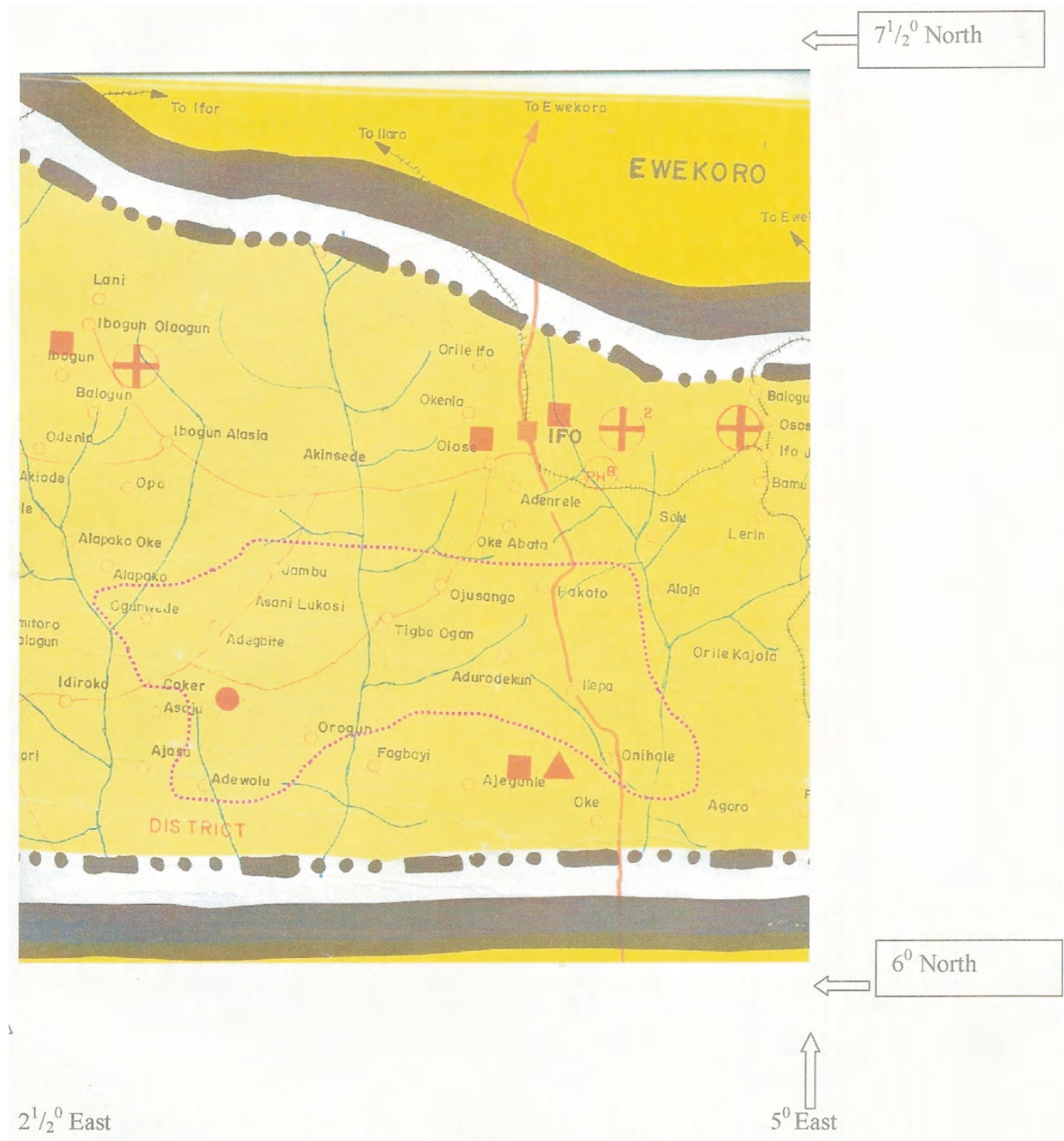

Source: Institute of Child Health and Primary Care, CMUL, Lagos.

Area of study encircled in broken points

Figure 1: Map showing the area of Study 
Figure 2: Bar chart showing frequency/percent of age distribution

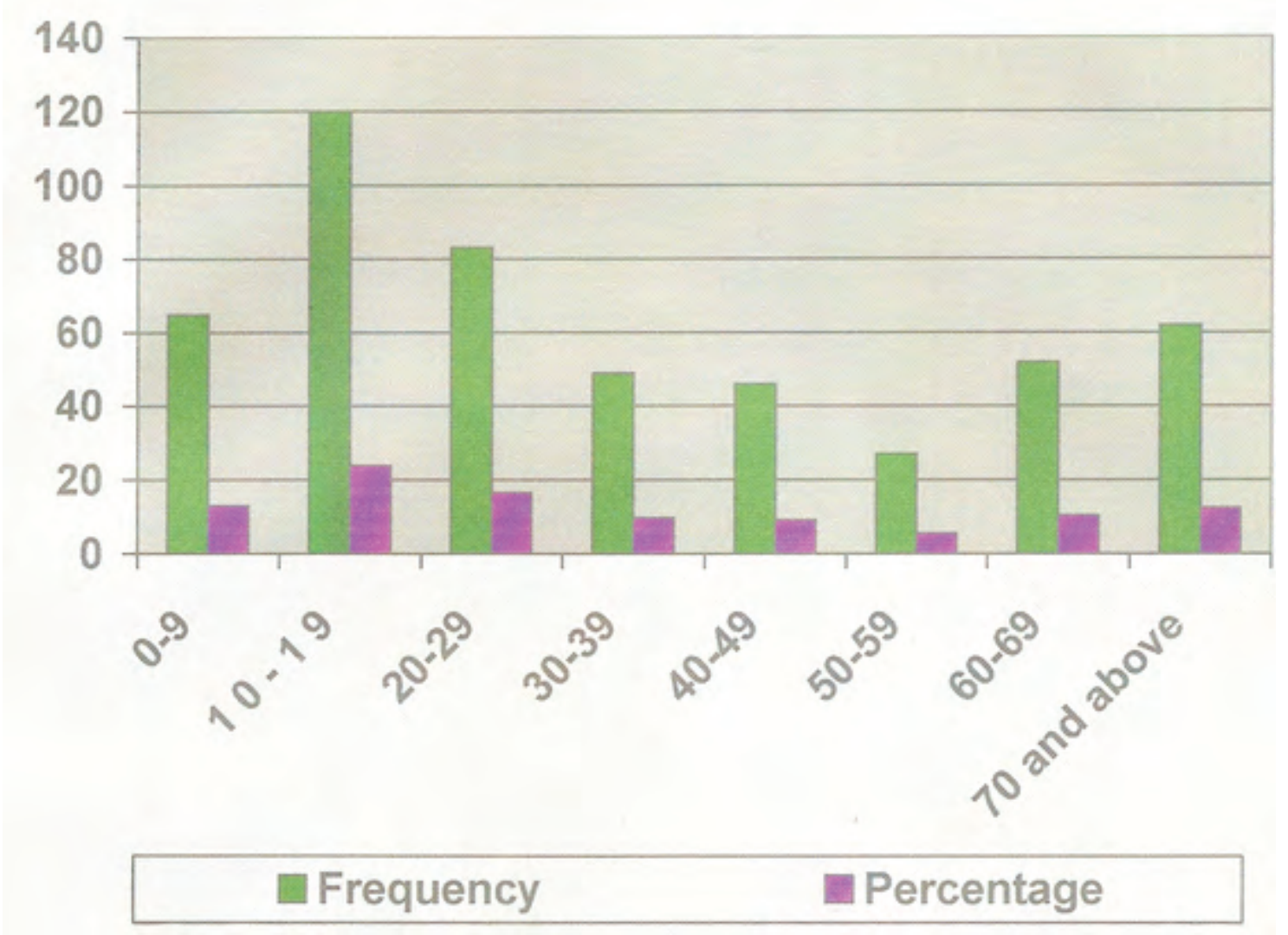

